\title{
Effects of artificial shelters (Casitas) on the abundance and biomass of juvenile spiny lobsters Panulirus argus in a habitat-limited tropical reef lagoon
}

\author{
Patricia Briones-Fourzán*, Enrique Lozano-Álvarez \\ Universidad Nacional Autónoma de México, Instituto de Ciencias del Mar y Limnología, Unidad Académica Puerto Morelos, \\ PO Box 1152 Cancún, Quintana Roo 77500, Mexico
}

\begin{abstract}
Casitas' are artificial habitats that mimic large crevice-type shelters sought by juvenile Caribbean spiny lobsters Panulirus argus. Despite the widespread use of casitas for lobster fishing in the Caribbean, the ecological performance of casitas is not yet fully understood. We examined the mode of operation of casitas in a habitat-limited population of juvenile $P$. argus in the reef lagoon at Puerto Morelos, Mexico. The density of juveniles in the reef lagoon was estimated with transects as $11 \mathrm{ha}^{-1}$. After the transect surveys, a year-long baseline study on the lobster population, consisting of 13 visual censuses, was conducted at 9 fixed sites, each of area $100 \times 100 \mathrm{~m}$ (1 ha). All lobsters were juveniles (10.7 to $56.5 \mathrm{~mm}$ carapace length, CL), and only $12 \%$ measured $>35 \mathrm{~mm}$ CL. No movement of tagged lobsters was recorded among sites. Overall density in the 9 sites was 5.0 ha $^{-1}$, but density varied widely in space and time. Two groups of sites were evident: a group of 5 sites with virtually no lobsters (NL sites), and a group of 4 sites with lobsters (WL sites). Lobster density was related to the abundance and size of natural shelters in each site. Casitas were deployed in 2 of the 4 WL and 3 of the $5 \mathrm{NL}$ sites (treatment sites), and further bimonthly censuses were conducted in all sites for an additional year. Despite temporal variations, lobster density in both WL and NL treatment sites increased significantly compared to control sites and to their respective baseline values. The mean size of lobsters and the biomass of all lobsters became gradually larger in treatment sites compared to control sites and to the baseline study, but both mean size and biomass fluctuated in time. These results support the hypothesis that artificial habitats increase the abundance and biomass of lobsters in habitat-limited environments, and the notion of an attraction-production continuum effect of casitas on lobsters.
\end{abstract}

KEY WORDS: Artificial habitats · Casitas · Spiny lobsters · Panulirus argus · Habitat limitation · Attraction-production · Mexican Caribbean

Resale or republication not permitted without written consent of the publisher

\section{INTRODUCTION}

Artificial reefs and aquatic habitats offer a potential opportunity for improving habitat, increasing resources, and manipulating assemblages of organisms (Bohnsack et al. 1991). Artificial habitats have been used in artisanal and commercial fisheries throughout the world, and also for environmental mitigation and

*E-mail: briones@mar.icmyl.unam.mx restoration. However, basic research on artificial habitats has often been neglected, and few studies have evaluated the ecological performance of artificial habitats experimentally (Miller 1999, Herrnkind et al. 1999).

Scientists have long debated on whether artificial habitats merely redistribute (attraction hypothesis) or actually increase the existing biomass (production hypothesis) of the targeted species (Polovina \& Sakai 1985, Bohnsack 1989, Polovina 1991). This 'attraction versus production' debate has prompted research on artificial habitats related to fisheries production (Miller 
1999), but studies have seldom incorporated temporal and spatial controls (Polovina \& Sakai 1985, Polovina 1991). Therefore the attraction versus production issue has been recently considered an unrealistic 'either-or' dichotomy, born from the lack of a proper experimental approach. Some authors (e.g. Bohnsack 1989, Bohnsack et al. 1997, Lindberg 1997, Sosa-Cordero et al. 1998) have proposed that attraction and production may not be mutually exclusive, but that a gradient or continuum may exist for their relative contribution, depending on local conditions.

Artificial shelters called 'casitas' have been used in Mexico for many decades to fish for the spiny lobster Panulirus argus, a major fisheries resource throughout the Caribbean Sea. Casitas consist of a flat roof bolted to a rectangular frame, and are built with materials ranging from palm trunks to ferro-cement (BrionesFourzán et al. 2000). Casitas are deployed in shallow, vegetated areas, and may harbor considerable numbers of lobsters. Lobsters that reach legal size are extracted from casitas by skin divers with hoop nets.

Depending on the size of the casitas and on the depth and type of habitat where they are deployed, casitas can be occupied by 1 or more of the gregarious, crevice-dwelling, benthic phases of Panulirus argus (Eggleston et al. 1990, Arce et al. 1997, Sosa-Cordero et al. 1998). These phases are: (a) post-algal juveniles (15 to $45 \mathrm{~mm}$ carapace length, CL), which emerge from their previous algal habitat in search for crevices; (b) subadults (45 to $80 \mathrm{~mm} \mathrm{CL);} \mathrm{and} \mathrm{(c)} \mathrm{adults} \mathrm{(>80} \mathrm{mm}$ CL) (Butler \& Herrnkind 1997).

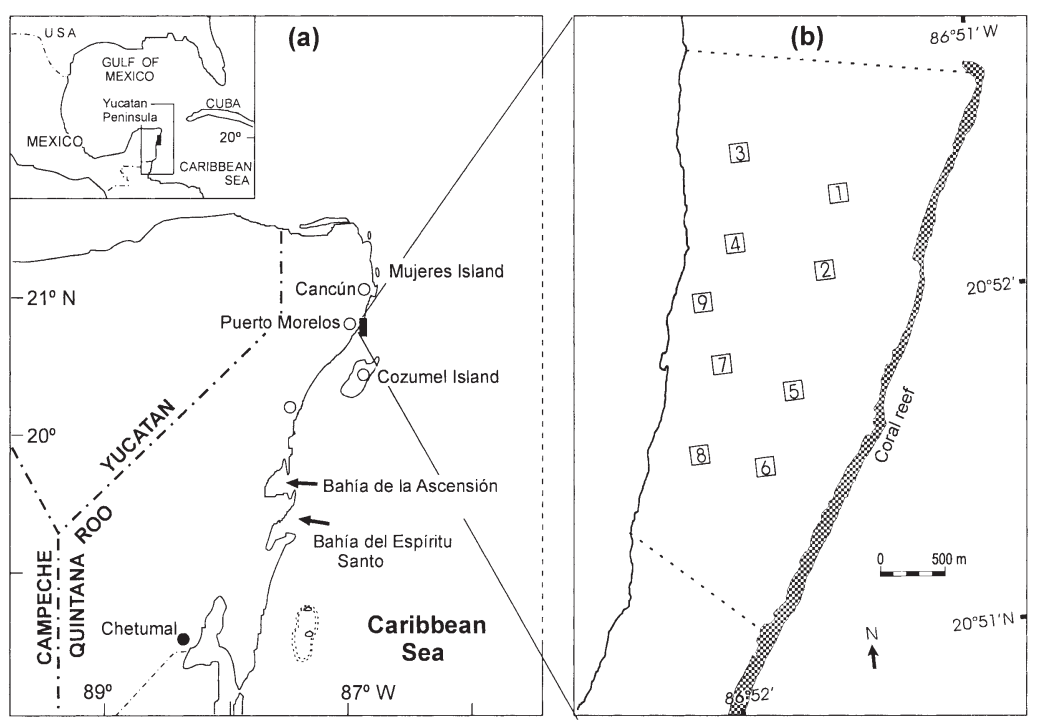

Fig. 1. Map of study area: (a) Caribbean coast of Mexico (state of Quintana Roo); (b) reef lagoon at Puerto Morelos. Dotted lines delimit area of lagoon surveyed by transects. Squares indicate locations of 9 sites (1 ha each) where lobster censuses conducted
Experimental work has shown that casitas increase the survival of juvenile lobsters by providing protection from predators (e.g. Eggleston et al. 1990, 1997, Eggleston \& Lipcius 1992, Mintz et al. 1994, SosaCordero et al. 1998). Casitas have also been used to study the dynamics of shelter selection by lobsters under variable social and environmental conditions (Eggleston \& Lipcius 1992, Eggleston et al. 1997, SosaCordero et al. 1998). To date, however, the ecological performance of casitas on lobster populations (i.e. whether casitas merely promote aggregation or actually increase biomass) has not been clearly established. To solve the attraction-production issue as related to casitas/lobsters, it would be necessary to experimentally test whether casitas can actually alter measures of lobster production, such as abundance, survival, growth, and biomass.

We conducted a field experiment at a large spatial scale in order to contrast the abundance, size and biomass of Panulirus argus in treatment (with casitas) and control (without casitas) sites. Before commencing the experiment, we performed a 1 yr baseline study on the existing lobster population in the study area, which would also serve as a time control. Such a study could only be conducted in a location where casitas had never previously been used, and preferably where no lobster fishing occurs, in order to fully control our habitat manipulation and to reduce the uncertainty as to the true number and sizes of lobsters under experimentation. The reef lagoon at Puerto Morelos, on the northeastern coast of Quintana Roo (Fig. 1) fulfilled these criteria.

The study was commenced in 1995 and consisted of 3 stages: (1) a gross evaluation of lobster abundance in the reef lagoon; (2) a baseline study on the monthly variability of lobster abundance and size distribution in fixed sampling sites throughout the study area; and (3) an experimental study involving the deployment of casitas in a number of those sites (treatment sites), leaving the remaining sites as controls. Our hypothesis was that if the lobster population in the reef lagoon was habitat-limited, the deployment of casitas would increase the abundance, size, and biomass of lobsters in treatment sites compared with control sites and with the baseline results.

\section{METHODS}

Study area. The reef lagoon at Puerto Morelos extends from the coastline to a 
shallow coral reef tract running slightly diagonally at a distance of $\sim 500$ to $2000 \mathrm{~m}$ from the coast (Fig. 1b). Depth in the reef lagoon is $\sim 1$ to $4 \mathrm{~m}$. No fishing for lobsters occurs in the reef lagoon and backreef area because lobsters in these places are undersize juveniles. Lobsters are caught offshore of the reef but in relatively small numbers and local fishermen prefer to catch lobsters at locations several kilometers to the north and south of Puerto Morelos (Lozano-Álvarez et al. 1991a, Padilla-Ramos \& Briones-Fourzán 1997).

The bottom of the lagoon consists mostly of calcareous sand, which is stabilized by extensive seagrass meadows. Ruiz-Rentería et al. (1998) divided the reef lagoon on the basis of its vegetation in the following 3 zones: (1) a narrow coastal fringe 20-50 m wide dominated by seagrass (either Thalassia testudinum or Syringodium filiforme with rhyzophitic algae); (2) a broad mid-lagoon zone 400-1000 m wide, where vegetation typically consists of a moderate density of $T$. testudinum with some $S$. filiforme and many species of rhyzophytic algae, particularly the brown alga Lobophora variegata; and (3) a backreef zone 100-400 m wide where short-bladed $T$. testudinum occurs but other plant species are scarce. The water temperature is typically higher in July-September, and lower during January-March. Monthly mean water temperature during the study period (Jul 1995-Aug 1999) ranged from $24.50^{\circ} \mathrm{C}$ (Feb 1996) to $30.06^{\circ} \mathrm{C}$ (Sep 1995).

Gross estimate of lobster abundance in the reef lagoon. Between July and November 1995, we estimated the overall abundance of lobsters throughout the reef lagoon at Puerto Morelos. The procedure involved conducting visual surveys for lobsters in 12 areas, $1600 \mathrm{~m}^{2}$ each, distributed in a number of transects in 12 combinations of width and length, in order to find the shape and number of transects most adequate for future comparative censuses (Pitcher et al. 1992). For example, we conducted 16 transects of $1 \times 100 \mathrm{~m}$ (i.e. $1600 \mathrm{~m}^{2}$ ), 16 of $2 \times 50 \mathrm{~m}, 16$ of $4 \times 25 \mathrm{~m}, 8$ of $1 \times 200 \mathrm{~m}, 8$ of $2 \times 100 \mathrm{~m}$, and so on. This gave a total of 90 transects with mean and variance estimations for each of the 12 combinations of length and width. A large area of the reef lagoon (Fig. 1b) was divided into a grid of squares $200 \times 200 \mathrm{~m}$, and transects were randomly allocated to squares. The direction of the transects was also randomly set. Transect lines were deployed during the daytime, when lobsters are inactive and shelter in their refuges. Two SCUBA divers checked each transect for lobsters. One diver was positioned either side of the line, holding a perpendicular rod measuring half the width of the transect; when a lobster was found, the diver recorded the type of shelter it occupied.

Baseline study on fixed sites. This method consisted of a monthly visual census for lobsters at fixed sites. To assess the utility of this method, in February 1996 a pilot fixed site was delimited with a nylon rope, forming a $100 \times 100 \mathrm{~m}$ square (1 ha), at a distance of $\sim 60 \mathrm{~m}$ from the coast (Fig. 1b, Site 9). This was surveyed for lobsters each month from April 1996 to October 1997. Additional parallel lines were deployed every $10 \mathrm{~m}$ in order to facilitate the search for lobsters within the delimited area. Three divers thoroughly searched for lobsters in the whole hectare, going between every 2 parallel lines at a time. Lobsters were caught by hand and carapace length (CL) was measured in situ using calipers $( \pm 0.1 \mathrm{~mm})$. In order to assess their movement range, juveniles were tagged (also in situ) with individually numbered 'spaghetti' type tags designed for small lobsters (Hallmark Ltd, Holden Hill, South Australia). Tags were inserted in the dorsolateral muscle between the carapace and the abdomen (LozanoÁlvarez et al. 1991b), and juveniles were released in the same place as they were captured. Spaghetti-type tags are widely used in lobster research because they are retained through several molts and have negligible deleterious effects on lobsters (Lozano-Álvarez 1992, Moriyasu et al. 1995), unless they are very small ( $\leq 20 \mathrm{~mm}$ CL, Forcucci et al. 1994). Therefore, only juveniles $\geq 25 \mathrm{~mm}$ CL and with a hard exoskeleton (i.e. intermolt stage) were tagged.

In February/March 1997, 8 additional sites of 1 ha each were delimited throughout the reef lagoon (Fig. 1b). To keep the sites as similar as possible, we distributed them only in the mid-lagoon zone (RuizRentería et al. 1998). Depth in all sites ranged between 2.5 and $3.5 \mathrm{~m}$. Because the sites were intended to serve as independent replicates, a minimum distance of $200 \mathrm{~m}$ was left between adjacent sites, based on the range of movements exhibited by juvenile Panulirus argus (Lozano-Álvarez et al. 1991b, Butler \& Herrnkind 1997). Thirteen lobster censuses were conducted at Sites 1-8 between April 1997 and April 1998, and in July 1998, in a similar manner as for pilot Site 9. At the end of the baseline study, we compared the abundance of lobsters among sites with a 1-way repeated measures ANOVA (Winer 1971), and the size distribution of lobsters among sites with a simple 1-way ANOVA.

To explore the relationship between lobster abundance with the presence and size of natural crevicetype shelters, potential shelters in each site were counted and categorized in 3 size classes: small $(<25 \mathrm{~cm}$ across the longest diameter), medium $(25-50 \mathrm{~cm})$ and large $(>50 \mathrm{~cm})$ (Childress \& Herrnkind 1997). These potential shelters consisted of loose calcareous rocks, pieces of dead coral, small heads of live scleractinian corals (e.g. Montastrea annularis and $M$. cavernosa), a few solution holes, and empty shells of the conch Strombus gigas.

Experimental study. Once the baseline study was finished, the experimental design involved deploying 
casitas on 5 of the 9 sites (including the pilot site 9) and leaving the remaining 4 as controls. However, during the baseline study, 5 of the 9 sites consistently yielded 0 lobster counts. This resulted in 2 groups of sites, i.e. 4 sites 'with lobsters' (WL) and 5 sites with 'no lobsters' (NL). To fully explore the effect of casitas on lobster abundance and biomass it became necessary to deploy casitas in some WL sites and some NL sites, although this reduced the number of replicates in each site group. Thus, we deployed casitas in 2 of the 4 WL sites (Sites 2 and 5) and in 3 of the 5 NL sites (Sites 4, 7 and 8) (treatment sites). Treatment sites in each group were randomly chosen. The remaining 2 WL (Sites 6 and 9) and 2 NL sites (Sites 1 and 3) were left as controls.

We scaled casitas to the size range of lobsters in the lagoon (Eggleston et al. 1990, 1997, Arce et al. 1997), which were mostly postalgal juveniles. The casitas consisted of a frame measuring $0.90 \times 1.20 \mathrm{~m}$, built with PVC pipes $3.8 \mathrm{~cm}$ in diameter, and a flat ferrocement roof attached to the frame. Ten casitas were deployed in each of the $2 \mathrm{WL}$ and 3 NL treatment sites. Because of the short movement range of postalgal juveniles (this study and Smith \& Herrnkind 1992, Butler \& Herrnkind 1997) the casitas were separated by at least $20 \mathrm{~m}$. To do this, each treatment site was divided in 25 squares measuring $20 \times 20 \mathrm{~m}$. Ten squares were chosen at random, and 1 casita was deployed in the center of each chosen square. Thus, if 2 contiguous squares were chosen by chance, there would be at least $20 \mathrm{~m}$ between their respective casitas.

The 50 casitas $(10$ casitas $\times 5$ treatment sites) were deployed in July 1998, after the final pre-casita census. Censuses were continued every $\sim 2$ mo for an additional year. Sites were surveyed in the same way as before the deployment of casitas but, in addition, each casita was examined in the treatment sites. This was performed by raising one side of the casita to expose the sheltering lobsters. During the experimental study, lobsters were neither hand-caught nor tagged; instead, their carapace length was estimated in $5 \mathrm{~mm}$ intervals with a template (a T-ruler with rods of 10, 15, 20 etc. mm glued on its short arm). At the end of the experimental study, we compared the lobster abundance between control and treatment sites with a 2-factor repeated measures ANOVA, with time as the repeated factor (Winer 1971). We also compared the abundance of lobsters in each group of sites throughout the baseline and experimental studies in a similar fashion. The size distribution of lobsters was compared between treatment and control sites, and between the baseline and experimental studies, with a Student's $t$-test. To explore the effect of casitas on the biomass of lobsters, we transformed the CL data to total weight (TW, g) by applying the equation: Log TW $=2.7511$ (Log CL) - 2.6243, obtained by Castañeda (1998) from 182 Panulirus argus (11.1-80.7 mm
CL) captured in the reef lagoon and at the coral reef at Puerto Morelos during January-November 1995, i.e. prior to the present study.

\section{RESULTS}

\section{Gross estimate of lobster abundance}

The 90 belt transects covered an area of $19200 \mathrm{~m}^{2}$ (1.92 ha), widely distributed throughout the reef lagoon. Only 22 lobsters were observed in 14 of these transects, yielding an average estimate of 11.5 lobsters $\mathrm{ha}^{-1}$. Lobsters were not measured at this stage, but they were all small juveniles. Seven lobsters were found sheltering under the base of small coral mounds, 5 in solution holes, 5 under loose rocks, 4 in empty conch shells, and 1 in a discarded tire. The paucity of lobsters precluded the estimation of means and variances for each combination of transect width and length, rendering this method unpractical for future surveys. However, this method provided an independent gross estimate of lobster abundance throughout the reef lagoon.

\section{Baseline study}

Lobster abundance

Data obtained at Site 9 from April 1996 to April 1997, and in July 1997, were compared with abundance data for the remaining 8 sites during the baseline study (Table 1). The number of lobster observations in all 9 sites was 586. However, the distribution of lobsters in the sites was highly heterogeneous. Sites 1, 3, 4, 7 and 8 (NL sites) consistently yielded zero counts, with an occasional 1 to 3 lobsters. In contrast, Sites 2, 5, 6 and 9 (WL sites) always contained lobsters (Table 1). Although numbers of lobsters varied with time, no significant differences in lobster abundance were found among the $4 \mathrm{WL}$ sites $(F=1.733$, df $=3,12, \mathrm{p}=0.10)$. The overall average density of lobsters in the 9 sites (5.0 ha ${ }^{-1}$, monthly range 2.8 to $8.0 \mathrm{ha}^{-1}$, Table 1 ) was lower than the average density obtained with the transects. However, the average density varied among WL sites, from $6.7 \mathrm{ha}^{-1}$ in Site 6 to $20.2 \mathrm{ha}^{-1}$ in Site 2 (Table 1).

These results were related to the number of shelters in the sites. NL sites contained virtually no shelters, whereas WL sites all had a number of potential shelters (Table 2). However, many of these shelters, especially the small and medium-sized, did not harbor lobsters and not all shelters in a particular site were used by lobsters. For example, although Site 6 had the largest 
Table 1. Number of lobsters and average density $\left(\mathrm{ha}^{-1}\right)$ observed in Sites 1-9 during baseline study in reef lagoon, Puerto Morelos. WL ('with lobsters') sites contained lobsters in all censuses, whereas NL ('no lobsters') sites consistently yielded zero counts. Each site 1 ha. ( ${ }^{*}$ Site 9 for same months in 1996)

\begin{tabular}{|c|c|c|c|c|c|c|c|c|c|c|c|}
\hline \multirow{2}{*}{$\begin{array}{l}\text { Month of } \\
\text { census }\end{array}$} & \multicolumn{4}{|c|}{ Sites with lobsters (WL) } & \multicolumn{5}{|c|}{ Sites with no lobsters (NL) } & \multirow{2}{*}{$\begin{array}{c}\text { Total } \\
\text { lobsters }\end{array}$} & \multirow{2}{*}{$\begin{array}{l}\text { Average } \\
\text { density }\end{array}$} \\
\hline & 2 & 5 & 6 & $9^{*}$ & 1 & 3 & 4 & 7 & 8 & & \\
\hline \multicolumn{12}{|l|}{1997} \\
\hline April & 11 & 2 & 5 & 14 & 0 & 0 & 0 & 0 & 0 & 32 & 3.6 \\
\hline May & 12 & 7 & 2 & 5 & 0 & 1 & 0 & 0 & 0 & 27 & 3.0 \\
\hline July & 22 & 7 & 8 & 12 & 0 & 2 & 0 & 0 & 0 & 51 & 5.7 \\
\hline August & 31 & 11 & 15 & 4 & 0 & 0 & 0 & 0 & 0 & 61 & 6.8 \\
\hline September & 31 & 8 & 16 & 16 & 1 & 0 & 0 & 0 & 0 & 72 & 8.0 \\
\hline October & 31 & 16 & 12 & 1 & 0 & 1 & 3 & 0 & 0 & 64 & 7.1 \\
\hline November & 23 & 15 & 6 & 15 & 0 & 0 & 0 & 0 & 0 & 59 & 6.6 \\
\hline December & 12 & 6 & 4 & 24 & 0 & 0 & 0 & 0 & 0 & 46 & 5.1 \\
\hline \multicolumn{12}{|l|}{1998} \\
\hline January & 29 & 7 & 2 & 8 & 0 & 0 & 0 & 0 & 1 & 47 & 5.2 \\
\hline February & 18 & 5 & 3 & 6 & 0 & 0 & 0 & 0 & 0 & 32 & 3.6 \\
\hline March & 10 & 5 & 5 & 5 & 0 & 0 & 0 & 0 & 0 & 25 & 2.8 \\
\hline April & 21 & 6 & 1 & 3 & 0 & 0 & 0 & 0 & 0 & 31 & 3.4 \\
\hline July & 12 & 12 & 8 & 7 & 0 & 0 & 0 & 0 & 0 & 39 & 4.3 \\
\hline Total lobsters & 236 & 107 & 87 & 120 & 1 & 4 & 3 & 0 & 1 & 586 & \\
\hline Average density & 20.2 & 8.2 & 6.7 & 9.2 & 0.1 & 0.3 & 0.2 & $\mathbf{0}$ & 0.1 & & 5.0 \\
\hline
\end{tabular}

number of shelters, it did not have the highest mean number of lobsters (Table 2). These results indicate habitat-limitation of the lobster population in the reef lagoon.

\section{Size distribution}

Size range of lobsters in pilot Site 9 was 12.0 to $56.5 \mathrm{~mm}$ CL (mean $\pm \mathrm{SD}, 30.73 \pm 9.93)$. At Sites 1 to 8 lobsters ranged in size from 10.7 to $55.5 \mathrm{~mm}$ CL (mean $\pm \mathrm{SD}, 22.97 \pm 9.01)$. The size distribution was strongly skewed towards the smaller sizes, i.e. algal and postalgal juveniles. No significant differences in lobster size were found among Sites 2, 5 and 6 (log-transformed data, $F=0.758, \mathrm{df}=2,420, \mathrm{p}=0.47$ ). Therefore, all the data from April 1997 to April 1998 were grouped to analyze the monthly size distribution of lobsters in the reef lagoon (Fig. 2). Juveniles $\leq 25 \mathrm{~mm}$ CL were generally more prevalent, whereas juveniles $>35 \mathrm{~mm}$ CL were scarce, accounting for $12 \%$ of the total lobster observations.

\section{Movements}

Overall, only 184 juveniles met the requirements for tagging and only 32 $(17.4 \%)$ were recaptured. Three juve- niles were recaptured twice, but only 1 of them remained at large for 3 mo. The rest were recaptured once, after 1 or 2 mo at large. The low percentage of recaptures and the short period in which lobsters remained at large suggest a high natural mortality rate. Emigration could also account for the low recaptures, but lobsters in the size range of our tagged individuals (mean $\pm \mathrm{SD}, 34.0 \pm 6.7 \mathrm{~mm} \mathrm{CL}$ ) do not move long distances. Juveniles were always recaptured at the same site where they had been initially captured and tagged. Distance from the place of initial capture was short: 12 juveniles were recaptured in the same shelter, 5 juveniles at $\leq 10 \mathrm{~m}$ distance, 9 at 11 to $20 \mathrm{~m}, 1$ at $30 \mathrm{~m}$, and 1 at $40 \mathrm{~m}$ (distance of recapture of the remaining 4 juveniles was not recorded). These results further indicate low mobility

Table 2. Number of shelters in Sites 1-9 (longest diameter: small, $<25 \mathrm{~cm}$; medium, $25-50 \mathrm{~cm}$; large, $>50 \mathrm{~cm}$ ), and average number of lobsters per site, April 1997-April 1998 and July 1998 (except Site 9, April 1996-April 1997 and July 1997)

\begin{tabular}{|c|c|c|c|c|c|c|c|c|c|}
\hline \multirow[t]{2}{*}{ No. of shelters } & \multicolumn{4}{|c|}{ Sites with lobsters (WL) } & \multicolumn{5}{|c|}{ Sites with no lobsters (NL) } \\
\hline & 2 & 5 & 6 & 9 & 1 & 3 & 4 & 7 & 8 \\
\hline Small & 86 & 41 & 245 & 14 & 2 & 2 & 0 & 0 & 1 \\
\hline Medium & 39 & 7 & 89 & 21 & 0 & 1 & 0 & 0 & 0 \\
\hline Large & 13 & 8 & 39 & 34 & 0 & 3 & 0 & 0 & 0 \\
\hline Total shelters & 138 & 56 & 373 & 69 & 2 & 6 & 0 & 0 & 1 \\
\hline $\begin{array}{l}\text { Average no. } \\
\text { of lobsters }\end{array}$ & 20.2 & 8.2 & 6.7 & 9.2 & 0.1 & 0.3 & 0.2 & 0.0 & 0.1 \\
\hline
\end{tabular}



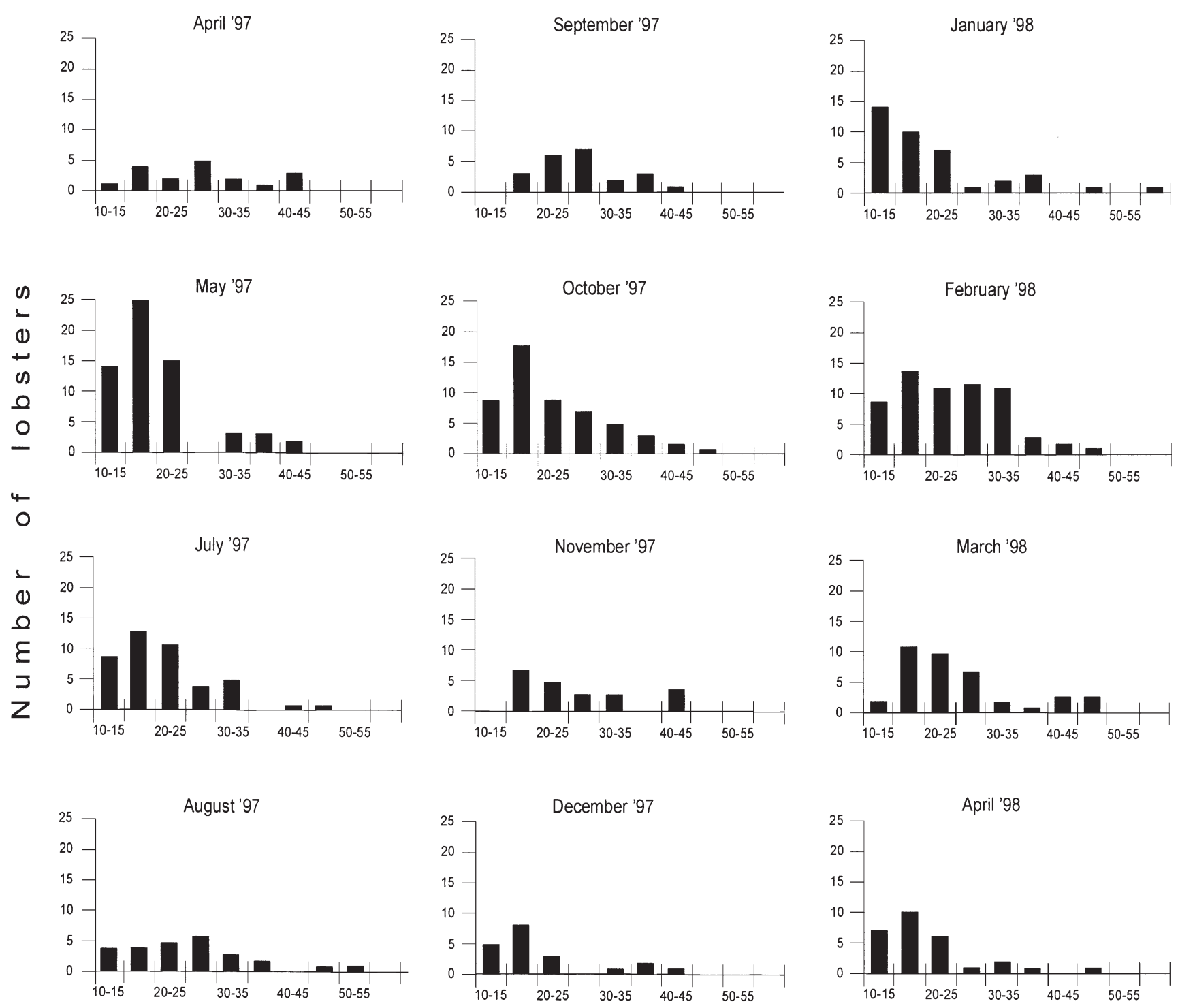

\section{Carapace length ( $\mathrm{mm}$ )}

Fig. 2. Panulirus argus, monthly size distribution (carapace length) of juveniles in Sites 1-8, reef lagoon at Puerto Morelos, April 1997-April 1998

of juveniles and high shelter fidelity (Butler \& Herrnkind 1997), and also that the distance of $200 \mathrm{~m}$ between adjacent sites was sufficient to ascertain the independence of sites.

\section{Experimental study}

Changes in lobster abundance

Untransformed data were used to assess changes in abundance between the baseline and experimental studies because they did not contradict the assumptions of homogeneity of variances (Cochran's test, $\alpha=$ 0.05, Winer 1971, Underwood 1981). Treatment WL sites showed a significant increase in lobster abundance after the deployment of casitas $(F=8.28$, df $=$ $1,15, \mathrm{p}<0.001)$, whereas control WL sites did not $(F=$ 2.081, df $=1,15, \mathrm{p}=0.10$ ) (Fig. 3a). The increase in lobster abundance as an effect of casitas was also evident in treatment NL sites (Fig. 3b), but in this case statistical analyses were not attempted because the extremely large number of zero values, in all NL sites throughout the baseline study and in NL control sites 
during the experimental study (Table 1, Fig. 3b), precluded the homogenization of variance even after appropriate transformations (Underwood 1981).

During the experimental study alone, the average number of lobsters per site group showed an evident effect of casitas on lobster abundance (Fig. 4a). Treatment sites (both WL and NL) had more lobsters than their respective control sites. The 2-way repeatedmeasures ANOVA showed a significant site effect (treatment, control) in lobster abundance $(F=40.59$, $\mathrm{df}=1,2, \mathrm{p}<0.05)$, but no significant time effect $(F=$ 0.567 , df $=5,5, \mathrm{p}>0.50$ ) nor time/site interaction effect $(F=0.425, \mathrm{df}=5,10, \mathrm{p}>0.50)$ were found. A NewmanKeuls test on group means clearly separated treatment sites from control sites. This indicates a strong effect of casitas on lobster abundance, independent of time. Although the power of this test was low because of the reduced number of replicates in each group of sites, the average number of juvenile lobsters in treatment WL sites (76.9) was over 5 times higher than before the deployment of casitas (14.2). Similarly, the average number of lobsters in treatment NL sites increased from 0.14 during the baseline study to 16.8 during the experimental study.

\section{Size and biomass of lobsters in treatment and control sites}

The overall size range of lobsters in the reef lagoon after the deployment of casitas was 9.0 to $60.0 \mathrm{~mm} \mathrm{CL}$ $($ mean $\pm \mathrm{SD}, 27.61 \pm 10.03)$, significantly larger than during the baseline study $(t=4.862$, df $=2042$, p < 0.001). Also, lobster size was significantly larger in treatment sites $(28.4 \pm 9.8 \mathrm{~mm} \mathrm{CL})$ than in control sites $(21.8 \pm 9.6 \mathrm{~mm} \mathrm{CL})(t=8.584, \mathrm{df}=1459, \mathrm{p}<0.001$, Fig. 4b). During the baseline study, most of the lobsters were juveniles smaller than $35 \mathrm{~mm}$ CL (see Fig. 2), which do not move much. Hence, the amount of juveniles < $35 \mathrm{~mm}$ CL after casita deployment provides an estimate of local settlers that survived in treatment sites due to the protective effect of casitas on small juveniles. In contrast, the amount of lobsters $>35 \mathrm{~mm}$ CL could indicate an attraction effect of casitas since these sizes are more mobile (Herrnkind et al. 1999), and/or an increase in size of local settlers due to the protection of casitas. In September 1998, 2 mo after the deployment of casitas, the mean size of juveniles in treatment sites was $<25 \mathrm{~mm} \mathrm{CL}$ (Fig. 4b) and the percentage of juveniles $>35 \mathrm{~mm}$ CL was negligible (Fig. 4c). The latter gradually increased until February 1999 then decreased in April and increased again in June 1999 (Fig. 4c). The average biomass of all the lobsters per site group was also higher in treatment than in control sites (Fig. 4d), but the lower biomass in treat-
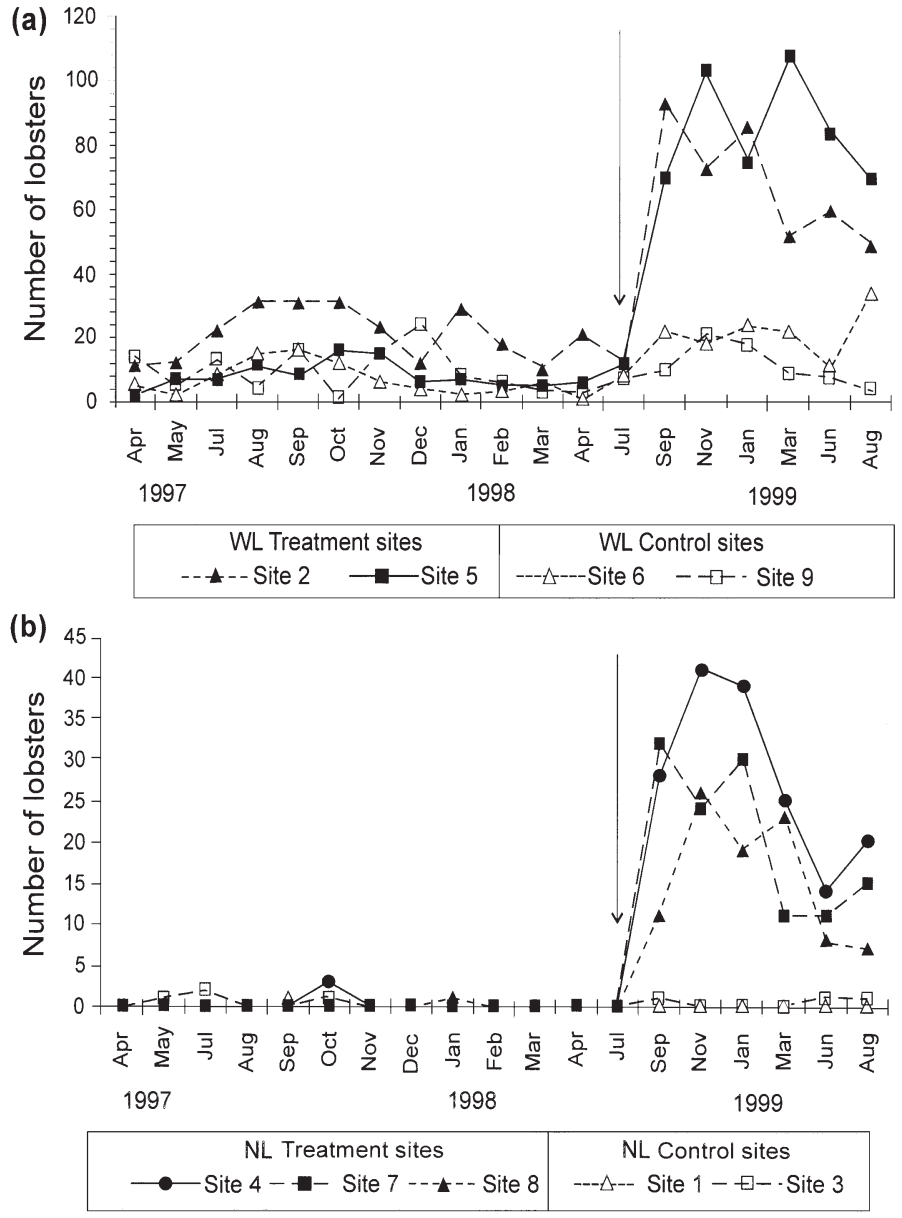

Fig. 3. Panulirus argus, density of juveniles $\left(\mathrm{ha}^{-1}\right)$ throughout the baseline and experimental studies in: (a) each of the WL ('with lobsters') sites; and, (b) each of the NL ('no lobsters') sites. Arrow in each graph indicates time of deployment of casitas in treatment sites (July 1998)

ment sites during September 1998 and April 1999 suggests a recruitment of small juveniles and/or an emigration of large juveniles, which was confirmed by the bimonthly size distribution of lobsters during the experimental study (Fig. 4b,c).

\section{Distribution of lobsters in casitas}

The distribution of lobsters beneath casitas was different in the 2 groups of treatment sites (Fig. 5). Casitas with no lobsters or only a few juveniles were more common in treatment NL sites than in treatment WL sites. In NL sites, the maximum number of lobsters in a single casita was 11 . In contrast, in WL sites casitas sheltering over 10 lobsters were common, and the maximum number of lobsters beneath a single casita was 50 . 


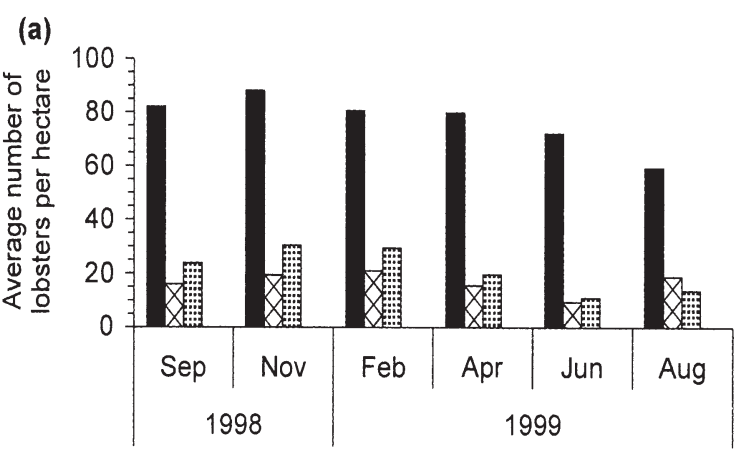

(b)

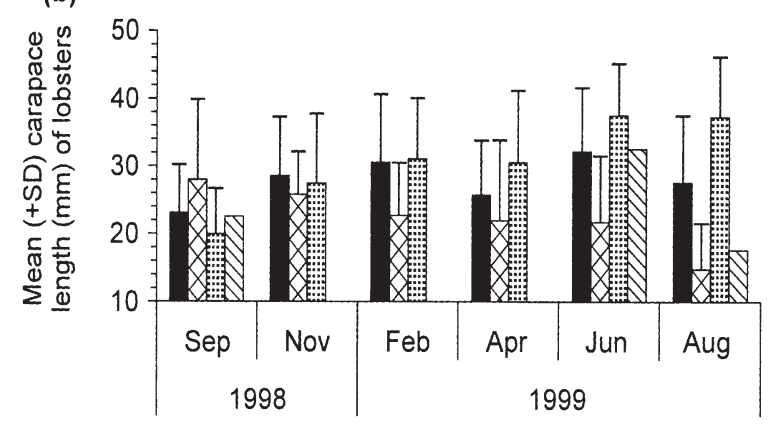

(c)

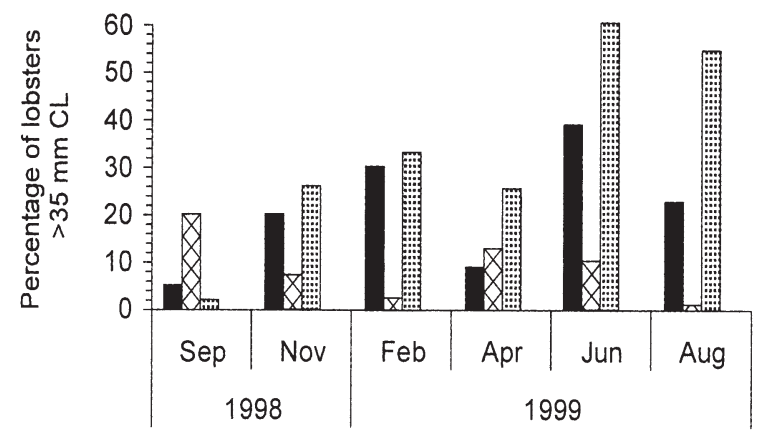

(d)

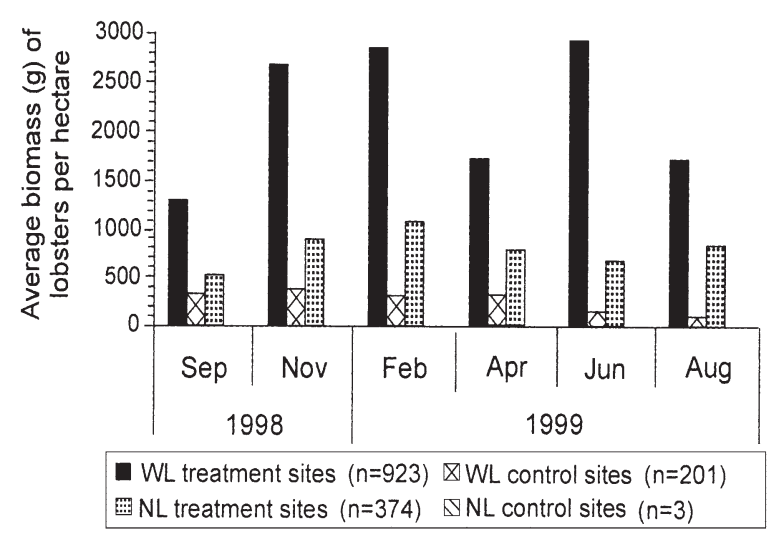

Fig. 4. Panulirus argus: (a) average number; (b) mean CL (+SD); (c) percentage $>35 \mathrm{~mm} \mathrm{CL}$; and, (d) average biomass per site group during experimental study. WL, sites with lobsters; NL, sites with no lobsters during the previous baseline study. Bimonthly censuses, September 1998-August 1999 ( $n=$ total number of lobsters observed in each group of sites)

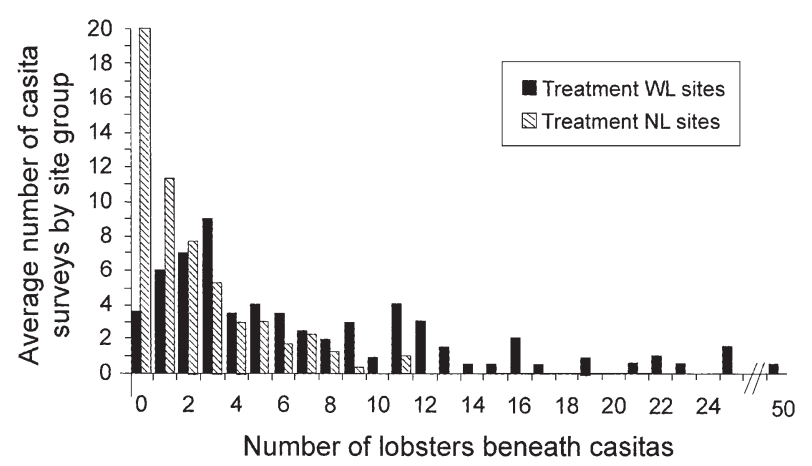

Fig. 5. Panulirus argus. Number sheltering beneath individual casitas in WL ('with lobsters') and NL ('no lobsters') treatment sites during the 6 bimonthly censuses after casita deployment. Total number of casitas surveyed were averaged in each group of sites ( $2 \mathrm{WL}, 3 \mathrm{NL}$ sites)

\section{DISCUSSION}

The extremely low abundance of postalgal juveniles of Panulirus argus in the reef lagoon at Puerto Morelos during the baseline study $\left(11.5 \mathrm{ha}^{-1}\right.$ in transects, $5.0 \mathrm{ha}^{-1}$ at fixed sites) suggests that this lobster population is habitat-limited. These densities were considerably lower than mean densities of similar-sized juvenile $P$. argus found in other locations. For example, Forcucci et al. (1994) estimated a mean of 454 postalgal juveniles ha ${ }^{-1}$ in Fiesta Key, Florida, through markrecapture methods, although by visual techniques their estimated mean was 152 juveniles ha ${ }^{-1}$. In Old Dan Bank, Florida, Butler \& Herrnkind (1997) found a mean of 6.3 juveniles in areas of 0.05 ha (i.e. 126 ha $^{-1}$ ).

When exploring the effects of artificial shelters on a population, other factors potentially limiting the abundance of target species, such as recruitment and food availability, should also be taken into account (Bohnsack et al. 1991, 1997, Butler \& Herrnkind 1997, Grossman et al. 1997). However, it seems unlikely that either postlarval recruitment or food availability underlie the scarcity of postalgal juveniles in Puerto Morelos. The monthly influx of pueruli to the reef lagoon at Puerto Morelos (as measured with artificial collectors since 1990) varies widely in time but occurs throughout the year, and has consistently been 3 to 5 times higher than in Bahía de la Ascensión (see Fig. 1a), where a highly successful casita-based fishery occurs (Briones-Fourzán 1994, Briones-Fourzán et al. 1998, 2000). In addition, the density of algal juveniles ( 6 to $20 \mathrm{~mm} \mathrm{CL}$ ) has been estimated as 146 to $263 \mathrm{ha}^{-1}$ in this reef lagoon. The preferred habitat of these small juveniles is the ruffled brown macroalga Lobophora variegata (Briones-Fourzán \& Lozano-Álvarez 2001) which grows in dense patches throughout the mid-lagoon zone. One hectare can hold 900 algal juveniles throughout the 
year, a value comparable to estimates in the Florida Keys (Marx \& Herrnkind 1985).

Food limitation for juvenile $P$. argus in the reef lagoon is also unlikely. Juveniles show no significant seasonal differences either in food intake or in nutritional state (Castañeda 1998), indicating that food is abundant year-round. The dominant food items in the stomach contents of these juveniles are small crustaceans and gastropods, which abound in the seagrass meadows in the reef lagoon throughout the year (Monroy-Velázquez 2000).

The ontogenetic shift from the algal habitat to crevice sheltering can potentially produce a population bottleneck (sensu Caddy 1986) for lobsters in areas devoid of appropriate structure (Childress \& Herrnkind 1994). Postalgal juveniles of $P$. argus live in crevice-type shelters mostly associated to hardbottom communities (Marx \& Herrnkind 1985, Herrnkind \& Butler 1986, Childress \& Herrnkind 1997) or among mangrove roots (Acosta \& Butler 1997). But in the reef lagoon at Puerto Morelos hardbottom areas are rare and mangroves are isolated from the sea by a coastal sand bar (Ruiz-Rentería et al. 1998). Thus, potential crevice-type shelters are scarce and overdispersed in the reef lagoon, and most are too small and/or not suitable for postalgal juveniles, as we found in our baseline study. Moreover, the few occupied natural shelters generally held a single, solitary juvenile, and many of our tagged juveniles remained in the same shelter between recaptures. A high shelter fidelity is related to a paucity of appropriate shelters (Acosta \& Butler 1997, Childress \& Herrnkind 1997).

Clearly then, habitat is the main limiting factor for Panulirus argus in this reef lagoon, causing a population bottleneck at the postalgal phase, as was further suggested by the low percentage of recaptures during the baseline study. Juveniles $<35 \mathrm{~mm}$ CL have shorter movement ranges (Forcucci et al. 1994, Butler \& Herrnkind 1997) and are more vulnerable to predators than larger lobsters (Smith \& Herrnkind 1992). Fish predators of $P$. argus include several species of sharks, rays, snappers, groupers, toadfishes, grunts, sciaenids, and triggerfishes (e.g. Randall 1967, Kanciruk 1980, Cruz et al. 1986, Smith \& Herrnkind 1992, PérezEspinosa 1993, Mintz et al. 1994, Lozano-Álvarez \& Spanier 1997). In Puerto Morelos grunts, snappers, groupers, sciaenids and triggerfishes are among the most abundant fish species (Álvarez-Guillén et al. 1986, Díaz-Ruiz et al. 1995). The combined effect of so many predators in an area almost devoid of adequate shelters may rapidly deplete the population of postalgal juveniles in this reef lagoon.

We believe that the significant increase in the abundance and biomass of juvenile Panulirus argus in our treatment sites was mostly due to the protection from predators provided by casitas (Eggleston et al. 1990, 1997), which allowed more juveniles to survive and attain less vulnerable sizes. Although casitas also attracted potential piscine predators, this does not necessarily imply an increase in predation rates on lobster juveniles in casitas (Arce et al. 1997, Eggleston et al. 1997, Sosa-Cordero et al. 1998). The cohabitation in casitas of juvenile $P$. argus and their potential predators is common in locations where casitas are used in the fishery (e.g. Lozano-Álvarez \& Spanier 1997, Cruz \& Phillips 2000) and small casitas such as the ones we used protect small lobsters more effectively than large casitas (Eggleston et al. 1990, 1997). Although we cannot rule out that some of these juveniles may fall prey to predators during their nocturnal foraging excursions (Mintz et al. 1994), we believe that the potential increase in predation-induced mortality is offset in time by the overall increase in juvenile abundance and biomass. A longer time-frame of study is needed in order to support this hypothesis.

The rapid increase in juvenile abundance in our treatment sites further underlines the paucity of suitable crevice-type shelters in this reef lagoon. The fast colonization of artificial structures in habitat-limited environments has been documented in lobsters (Scarratt 1968, Davis 1985, Cruz et al. 1986, Lozano-Álvarez et al. 1994, Butler \& Herrnkind 1997, Herrnkind et al. 1999), octopuses (Polovina \& Sakai 1985), and fishes (Bohnsack et al. 1991, Eklund 1997).

This rapid accumulation of individuals in artificial habitats shows the importance of aggregation during the initial colonization phase. But a mere increase in abundance is not a sufficient measure of the 'ecological currency' of artificial habitats (Bohnsack et al. 1991), because this greatly underplays other measures of ecological importance, such as size and biomass. In our treatment sites, casitas were initially colonized by small juveniles (mean size $<25 \mathrm{~mm} \mathrm{CL}$, see Fig. $4 \mathrm{~b}$,c). These juveniles were too small to have moved to casitas from places outside the experimental sites (Herrnkind et al. 1999); they were more likely attracted to casitas from the surrounding algal habitats during the first 2 mo following deployment of casitas. If casitas were merely attracting juveniles from other areas, then large juveniles (>35 mm CL) would have rapidly colonized the casitas because large juveniles are much more mobile than small juveniles. Juveniles $>35 \mathrm{~mm}$ CL only accounted for $12 \%$ of lobsters in the reef lagoon throughout the baseline study, so there were few large recruits to colonize the casitas. The size and biomass of lobsters in our treatment sites further increased throughout the following 2 surveys, decreased in April, and increased again in June. Cyclical or seasonal fluctuations in abundance and biomass around some average values are also common in trop- 
ical fish (Bohnsack et al. 1991) and lobsters (Herrnkind et al. 1999) colonizing artificial habitats. Fluctuations in the number, size, and biomass of lobsters in our treatment sites might have been caused by the dynamic interplay of temporal variations in the abundance of the smaller, algal juveniles (Briones-Fourzán \& Lozano-Álvarez 2001), differential seasonal growth rates (lower in winter, higher in summer, Lellis \& Russell 1990, Forcucci et al. 1994, Lozano-Álvarez \& Spanier 1997), and the eventual emigration of the larger juveniles from casitas.

This supports the notion that, after the rapid initial colonization of casitas by small juveniles (attraction phase), the refuge value of the casitas allowed these juveniles to survive and outgrow their more vulnerable postalgal phase (production phase), in an attractionproduction gradient that continues to operate when the larger juveniles emigrate from casitas to the nearby reef tracts and other, smaller juveniles emerge from the surrounding algal habitats in search of crevicetype shelters.

Nevertheless, treatment WL sites continued to harbor more lobsters than treatment NL sites, and casitas with few or no lobsters were more prevalent in treatment NL sites (Fig. 5). These results could be related to the initial density of lobsters, the size of the casitas, and a chemical-mediated attraction to casitas by conspecifics, as shown in different experimental works. It has been shown that areas with few fishes or low biomass on natural habitats would tend to have corresponding low values on artificial habitats; conversely, areas with abundant fishes or biomass on natural habitats would tend to have higher values on artificial habitats (Bohnsack 1989, Bohnsack et al. 1991). Artificial shelters experimentally deployed in several sites in Bahía de la Ascensión exhibited high numbers of lobsters only in those sites where the abundance of lobsters was already relatively high (Lozano-Álvarez et al. 1994). Eggleston \& Lipcius (1992) and Eggleston et al. (1997) found that at relatively high densities, small lobsters ( $\leq 45 \mathrm{~mm} \mathrm{CL}$ ) preferred to reside gregariously in large casitas with conspecifics rather than solitarily in small shelters, and conversely, small lobsters preferred to reside in small shelters when lobster abundance was low. However, in areas where shelters are sparse or widely scattered, large shelters commonly harbor groups of juveniles over a wide size range (this study and LozanoÁlvarez et al. 1991b, 1994, Arce et al. 1997, Butler \& Herrnkind 1997). Ratchford \& Eggleston (1998) found that conspecific scents emanating from a nearby shelter cause other lobsters to shift to that shelter, and that the production of the attracting odor may be massdependent, i.e. more lobsters co-denning in a shelter may release more scent. This chemical cue may reduce the exposure time of shelter-seeking juveniles, and hence their probability of being caught by a predator (Childress \& Herrnkind 1997, Herrnkind et al. 1999).

We believe that in our treatment WL sites, some casitas contained large numbers of lobsters because of the paucity of other suitable shelters and a relatively high initial density of small juveniles, resulting in rapid colonization of casitas. In treatment NL sites, juveniles were too scarce immediately after the deployment of casitas to occupy all the casitas. But once a juvenile moves to a casita, others may soon respond to its chemical cues and the group may eventually grow (attraction effect). Later on, when more lobsters move to a casita, the refuge value of the casita results in an increased survival and biomass of more lobsters (production effect). Thus, the attraction-production effect operated at different levels in WL and NL sites, at least during the timeframe of the study, because of differences in the overall conditions between both groups of sites.

The present study provides evidence that casitas increase the abundance and biomass of juvenile lobsters in habitat-limited environments, for which we advocate a combined attraction-production effect. However, we cannot extrapolate our results to the large-scale fisheries based on casitas because the effect of casitas was only explored throughout $1 \mathrm{yr}$. A longer timeframe might yield different results. For example, if the attraction-production effect continues to operate then perhaps the differences in juvenile abundance between WL and NL sites will become less marked as gradually more lobsters survive to a size where their movement range is increased. LozanoÁlvarez (1995) proposed that, in addition to providing protection from predators, the presence of casitas increases the foraging habitat of juvenile lobsters by providing them with alternative shelters of the same size and shape over a wider foraging area. This hypothesis also warrants further exploration.

Acknowledgements. We gratefully acknowledge the invaluable technical support of Fernando Negrete-Soto and Cecilia Barradas-Ortiz in field and laboratory activities, and the useful comments of 4 anonymous reviewers. Additional help in the field was provided by Verónica Castañeda, Erik Cadena, Surya Garza, Daniella Guevara, Jaime Estrada, Verónica Monroy, Patricia Rangel, and María Eugenia Ramos. Francisco Ruiz-Rentería provided processed data on water temperature. This study was funded by Consejo Nacional de Ciencia y Tecnología (Project 1171-N) and Universidad Nacional Autónoma de México. Field activities were possible thanks to 4 annual scientific fishing permits issued by the Secretary of the Environment, Natural Resources and Fisheries of Mexico.

\section{LITERATURE CITED}

Acosta CA, Butler MJ IV (1997) Role of mangrove habitat as nursery for juvenile spiny lobster, Panulirus argus, in Belize. Mar Freshw Res 48:721-727 
Álvarez-Guillén H, García-Abad MC, Tapia-García M, Villalobos-Zapata G, Yáñez-Arancibia A (1986) Prospección ictioecológica en la zona de pastos marinos de la laguna arrecifal en Puerto Morelos, Quintana Roo, México. An Inst Cienc del Mar y Limnol Univ Nal Autón México 13(3): 317-336

Arce AM, Aguilar-Dávila W, Sosa-Cordero E, Caddy JF (1997) Artificial shelters (casitas) as habitat for juvenile spiny lobsters Panulirus argus in the Mexican Caribbean. Mar Ecol Prog Ser 158:217-224

Bohnsack JA (1989) Are high densities of fishes at artificial reefs the result of habitat limitation or behavioral preference? Bull Mar Sci 44:631-645

Bohnsack JA, Johnson DL, Ambrose RF (1991) Ecology of artificial reef habitats and fishes. In Seaman W Jr, Sprage LM (eds) Artificial habitats for marine and freshwater fisheries. Academic Press, New York, p 61-107

Bohnsack JA, Eklund, AM, Szmant AM (1997) Artificial reef research: is there more than the attraction-production issue? Fisheries 22(4):14-16

Briones-Fourzán P (1994) Variability in postlarval recruitment of the spiny lobster, Panulirus argus (Latreille, 1804) to the Mexican Caribbean coast. Crustaceana 66:326-340

Briones-Fourzán P, Lozano-Álvarez E (2001) The importance of Lobophora variegata (Phaeophyta: Dictyotales) as a habitat for small juveniles of Panulirus argus (Decapoda: Palinuridae) in a tropical reef lagoon. Bull Mar Sci 68: 207-219

Briones-Fourzán P, Lozano-Álvarez E, Negrete-Soto F (1998) Reclutamiento de postlarvas (puerulos) de Panulirus argus en la laguna arrecifal de Puerto Morelos. In: BrionesFourzán P (ed) Funcionamiento de refugios artificiales para langosta y su impacto en hábitats de pastizal marino. Informe Final CONACYT-UNAM 1171-N, Universidad Nacional Autónoma de México, Puerto Morelos, p 121-142

Briones-Fourzán P, Lozano-Álvarez E, Eggleston DB (2000) The use of artificial shelters (Casitas) for research and harvesting of Caribbean spiny lobsters in Mexico. In: Phillips BF, Kittaka J (eds) Spiny lobsters: fisheries and culture, 2nd edn. Fishing News Books, Oxford, p 420-446

Butler MJ IV, Herrnkind WF (1997) A test of recruitment limitation and the potential for artificial enhancement of spiny lobster (Panulirus argus) populations in Florida. Can J Fish Aquat Sci 54:452-463

Caddy JF (1986) Modelling stock-recruitment processes in Crustacea: some practical and theoretical perspectives. Can J Fish Aquat Sci 43:2330-2344

Castañeda V (1998) Alimentación natural de los juveniles de la langosta Panulirus argus (Latreille, 1804). Tesis profesional, Universidad Nacional Autónoma de México

Childress MJ, Herrnkind WF (1994) The behavior of juvenile Caribbean spiny lobster in Florida Bay: Seasonality, ontogeny and sociality. Bull Mar Sci 54:819-827

Childress MJ, Herrnkind WF (1997) Den sharing by juvenile Caribbean spiny lobsters (Panulirus argus) in a nursery habitat: cooperation or coincidence? Mar Freshw Res 48: 751-758

Cruz R, Phillips BF (2000) The artificial shelters (Pesqueros) used for the spiny lobster (Panulirus argus) fisheries in Cuba. In: Phillips BF, Kittaka J (eds) Spiny lobsters: fisheries and culture, 2nd edn. Fishing News Books, Oxford, p 400-419.

Cruz R, Brito R, Díaz E, Lalana R (1986) Ecología de la langosta (Panulirus argus) al SE de la Isla de la Juventud. I. Colonización de arrecifes artificiales. Rev Inv Mar (Cuba) 7(3):3-17
Davis G (1985) Artificial structures to mitigate marina construction impacts on spiny lobsters, Panulirus argus. Bull Mar Sci 37:151-156

Díaz-Ruiz S, Pérez-Solís O, Aguirre-León A, Chávez-Rojas J, Ramos-Arroyo J (1995) Estructura y dinámica de la comunidad de peces del sistema arrecifal coralino de Puerto Morelos, Quintana Roo. Informe final Proyecto LIEC/ CBS/UAM-I, Universidad Autónoma Metropolitana, México:1-90

Eggleston DB, Lipcius RN (1992) Shelter selection by spiny lobster under variable predation risk, social conditions, and shelter size. Ecology 73:992-1011

Eggleston DB, Lipcius RN, Miller DL, Cobá-Cetina L (1990) Shelter scaling regulates survival of Caribbean spiny lobster, Panulirus argus. Mar Ecol Prog Ser 62:70-88

Eggleston DB, Lipcius RN, Grover JL (1997) Predator and shelter-size effects on coral reef fish and spiny lobster prey. Mar Ecol Prog Ser 149:43-59

Eklund AM (1997) The importance of post-settlement predation and reef resources limitation on the structure of reef fish assemblages. Panamá, June 24-29, 1996. Proc 8th Int Coral Reef Symp 2. Smithonian Tropical Research Institute, Balboa, p 1139-1142

Forcucci D, Butler MJ IV, Hunt JH (1994) Population dynamics of juvenile Caribbean spiny lobster, Panulirus argus, in Florida Bay, Florida. Bull Mar Sci 54:805-818

Grossman GD, Jones GP, Seaman WJ Jr (1997) Do artificial reefs increase regional fish production? A review of existing data. Fisheries 22(4):17-23

Herrnkind WF, Butler MJ IV (1986) Factors regulating postlarval settlement and juvenile microhabitat use by spiny lobsters Panulirus argus. Mar Ecol Prog Ser 34: 23-30

Herrnkind WF, Butler MJ IV, Hunt JH (1999) A case for shelter replacement in a disturbed spiny lobster nursery in Florida: why basic research had to come first. Am Fish Soc Symp 22:421-437

Kanciruk P (1980) Ecology of juvenile and adult Palinuridae (spiny lobsters). In: Cobb JS, Phillips BF (eds) The biology and management of lobsters. Vol 2. Ecology and management. Academic Press, New York, p 59-92

Lellis WA, Russell JA (1990) Effect of temperature on survival, growth and feed intake of postlarval spiny lobster Panulirus argus. Aquaculture 90:1-9

Lindberg WJ (1997) Can science resolve the attraction-production issue? Fisheries 22(4):10-13

Lozano-Álvarez E (1992) Pesquería, dinámica poblacional y manejo de la langosta Panulirus argus (Latreille, 1804) en Bahía de la Ascensión, Q R, México. Tesis Doctoral, Universidad Nacional Autónoma de México

Lozano-Álvarez E (1995) Requisitos para la introducción de refugios artificiales en pesquerías de langosta. Rev Cubana Inv Pesq 19(2):21-26

Lozano-Álvarez E, Spanier E (1997) Behaviour and growth of captive spiny lobsters (Panulirus argus) under the risk of predation. Mar Freshw Res 48:707-713

Lozano-Álvarez E， Briones-Fourzán P, González-Cano J (1991a) Pesca exploratoria de langostas con nasas en la plataforma continental del área de Puerto Morelos, Q R México. An Inst Cienc del Mar y Limnol Univ Nal Autón México 18(1):49-58

Lozano-Álvarez E, Briones-Fourzán P, Phillips BF (1991b) Fisheries characteristics, growth, and movements of the spiny lobster Panulirus argus in Bahía de la Ascensión, México. Fish Bull US 89:79-89

Lozano-Álvarez E, Briones-Fourzán P, Negrete-Soto F (1994) An evaluation of concrete block structures as shelter for 
juvenile Caribbean spiny lobsters, Panulirus argus. Bull Mar Sci 55:351-362

Marx JM, Herrnkind WF (1985) Macroalgae (Rhodophyta: Laurencia spp.) as habitat for young juvenile spiny lobsters, Panulirus argus. Bull Mar Sci 36:423-431

Miller MW (1999) Using 'natural' reef ecology in artificial reef research: advancing artificial reef goals through better understanding of ecological process. Proceedings of the 7th International Conference on Artificial Reefs and Habitats, Sanremo, Italy, October 1999. Società Italiana di Biologia Marina, Sanremo, p 37-44

Mintz JD, Lipcius RN, Eggleston DB, Seebo MS (1994) Survival of juvenile Caribbean spiny lobster: effects of shelter size, geographic location, and conspecific abundance. Mar Ecol Prog Ser 112:255-266

Monroy-Velázquez LV (2000) Variaciones en la composición y abundancia de la fauna de decápodos asociados a pastizales marinos en el Caribe mexicano. Tesis de Maestría en Ciencias, Universidad Nacional Autónoma de México

Moriyasu M, Landsburg W, Conan GY (1995) Sphyrion tag shedding and tag induced mortality on the American lobster, Homarus americanus H. Milne-Edwards, 1837 (Decapoda, Nephropidae). Crustaceana 68:184-192

Padilla-Ramos S, Briones-Fourzán P (1997) Biological characteristics of the spiny lobsters (Panulirus spp.) from the commercial catch in Puerto Morelos, Quintana Roo, Mexico. Cienc Marin 23:175-193

Pérez-Espinosa P (1993) Estudio preliminar sobre la depredación de las postlarvas y primeros estadios juveniles de la langosta espinosa, Panulirus argus (Latreille, 1804), en la región de Puerto Morelos, Q R Tesis profesional, Universidad Autónoma Metropolitana, México

Pitcher CR, Skewes TD, Dennis DM, Prescott JH (1992) Esti-

Editorial responsibility: Otto Kinne (Editor),

Oldendorf/Luhe, Germany mation of the abundance of the tropical lobster Panulirus ornatus in Torres Strait, using visual transect-survey methods. Mar Biol 113:57-64

Polovina JJ (1991) Fisheries applications and biological impacts of artificial habitats. In: Seaman W Jr, Sprage LM (eds) Artificial habitats for marine and freshwater fisheries. Academic Press, New York, p 153-176

Polovina JJ, Sakai I (1985) Impacts of artificial reefs on fishery production in Shimamaki, Japan. Bull Mar Sci 44: 997-1003

Randall JE (1967) Food habits of reef fishes of the West Indies. Stud Trop Oceanogr 5:655-847

Ratchford SG, Eggleston DB (1998) Size- and scale-dependent chemical attraction contributes to an ontogenetic shift in sociality. Anim Behav 56:1027-1034

Ruiz-Rentería F, van Tussenbroek BI, Jordán-Dahlgren E (1998) Puerto Morelos, Quintana Roo, Mexico. In: Kjerfve B (edn) CARICOMP: Caribbean coral reef, seagrass and mangrove sites. UNESCO, Paris, p 57-66

Scarrat DJ (1968) An artificial reef for lobsters (Homarus americanus). J Fish Res Board Can 25:2683-2690

Smith KN, Herrnkind WF (1992) Predation on early juvenile spiny lobsters, Panulirus argus (Lat.): influence of size and shelter. J Exp Mar Biol Ecol 64:1-16

Sosa-Cordero E, Arce AM, Aguilar-Dávila W, RamírezGonzález A (1998) Artificial shelters for spiny lobster Panulirus argus (Latreille): an evaluation of occupancy in different benthic habitats. J Exp Mar Biol Ecol 229:1-18

Underwood AJ (1981) Techniques of analysis of variance in experimental marine biology and ecology. Oceanogr Mar Biol Ann Rev 19:513-605

Winer BJ (1971) Statistical principles in experimental designs, 2nd edn. McGraw-Hill, New York

Submitted: May 23, 2000; Accepted: February 21, 2001 Proofs received from author(s): October 5, 2001 